\title{
Evaluation of the energy efficiency of an industrial consumer in trigeneration mode
}

\author{
Constantin Ionescu ${ }^{l}$, Diana Tuțică $^{I}$, Roxana Pătrașcu $^{l}$, Cristian Dincă ${ }^{l, *}$, and Nela Slavu ${ }^{l}$ \\ ${ }^{1}$ Energy Generation and Use Department, University POLITEHNICA of Bucharest, Splaiul Indep., 313, 060042, Bucharest, Romania
}

\begin{abstract}
The optimization of the energy supply solution of an industrial facility is a main objective of any management program within a company, having as desideratum: quality, safety and flexibility in energy supply. The electricity and heat supply (heat and cold) using a trigeneration plant is a modern technological solution, with high energy efficiency performance and low impact on the environment. Also, this technology is economically efficient, assuring the reduction of the global energy consumption of the industrial society, and implicitly the increasing of the profit. The input data considered in this paper are the values and the characteristics of the demands of the three energy forms belonging to the analysed industrial consumer. The structure of the thermal energy both as heat (technological steam, heating, domestic hot water) and cold (air conditioning) is considered. The consumption of the electricity covers the need of both the technological process and of the buildings (power supply and lighting). In a first stage, the most suitable technological solution for the specific conditions and characteristics of the needs is chosen. The multicriteria analysis of the proposed technological solution is performed during the next stage.
\end{abstract}

\section{Introduction}

Conceptually, trigeneration actually represents a cogeneration solution, in which heat and/or electric energy, produced in the cogeneration plant, are used simultaneously or alternately, partially and/or integrally, for cold production. Cold production, using cogenerated energies (heat or electric energy) can be done as follows:

- Heat usage in absorption refrigeration plants;

- Electric energy usage in refrigeration installations with mechanical vapor compression.

Depending on the two alternatives for obtaining cold, in this paper we will compare the two alternatives of trigeneration power plants (TCG) for energy supply (electric, heat, cold) of the industrial consumer [1].

The opportunity to implement a trigeneration plant (combined and simultaneous production of electric and thermal energy, heat and cold) results, on the one hand, from the analysis of the electrical and thermal energy consumed by the new energy source (a), but also from the analysis of the thermodynamic and technical performances that will be considered in the choice of the energy equipments related to the new source (b) in the case of the basic cogeneration solution. Generally, by its nature, the process of combined and simultaneous (cogeneration) production of two forms of electric power and heat achieves an effective primary fuel economy compared to the separate production of mechanical work (in a power plant) and heat in a thermal plant). This economy translates firstly into a reduction in fuel costs and secondly by reducing environmental pollution, by direct effect - reducing pollutant emissions, and indirectly
- reducing the degree of depletion of non-renewable natural resources. Eventual economic quantification of environmental effects, supported by legislative leverage, would increase the overall economic efficiency of the proposed solution $[2,3]$.

\section{Energy demand analysis of the industrial consumer}

In this present we analyse the opportunity of simultaneous and combined supply of an industrial company with electric and thermal energy (heat and cold), in the perspective of modifying the current solution of separated energy supply.

The annual working period of the industrial processes within the analysed company is 12 months per year and the weekly working regime is 7 days / week, the activity being organized in three shifts $(24 / 24 \mathrm{~h})$.

In the context of the above presented situation, it is necessary for the company's management to evaluate the possible technical alternatives for the thermal and cold electric power supply of the company in different alternatives. Electricity is used in the framework of the industrial contours analysed for the supply of technological consumers, chillers (cold production installations that provide air conditioning for industrial and administrative buildings) as well as domestic utilities of an electrical nature, having as desideratum: quality, safety and flexibility in the power supply.

The heat used has the following destinations:

- technological purpose - is of permanent character, it

\footnotetext{
Corresponding author: crisflor75@yahoo.com
} 
is in the form of saturated steam at the pressure of 8 bar (process parameters). The condensate is returned at a rate of $30 \%$ and the heat is recovered in a proportion of about $70 \%$ for the hot water preparation;

- heating of buildings - is aimed at providing thermal comfort both in industrial halls and in administrative buildings. This heat is in the form of hot water flowing in closed circuit at $80{ }^{\circ} \mathrm{C} / 60{ }^{\circ} \mathrm{C}$;

- DHW preparation - is in the form of hot water at 50 ${ }^{\circ} \mathrm{C}$ (according to SR 1478/90), used for sanitary purposes, in a very large proportion being prepared by recovering the heat of the condensate returned from technological processes.

The produced cold is designed to provide air conditioning for industrial halls as well as for administrative buildings $[1,4]$.

The main aspects considered when choosing the technological trigeneration solution are:

- annual usage times of electricity and heat demand (heat and cold);

- heat load structure (heat and cold);

- ranked curves aspect for electric and thermal energy (heat and cold), flattening degrees);

- instantaneous values of energy demands (maximum, average);

- consumption structure index.

Figures 1-3 show the ranked curves of demand for electricity, heat and cold. These were obtained by statistical processing of 34,250 numerical data (measured values), covering a total equivalent time of 357 days $(8500 \mathrm{~h} /$ year), representing $97.74 \%$ of the total of 365 days / year (8760 h / year).

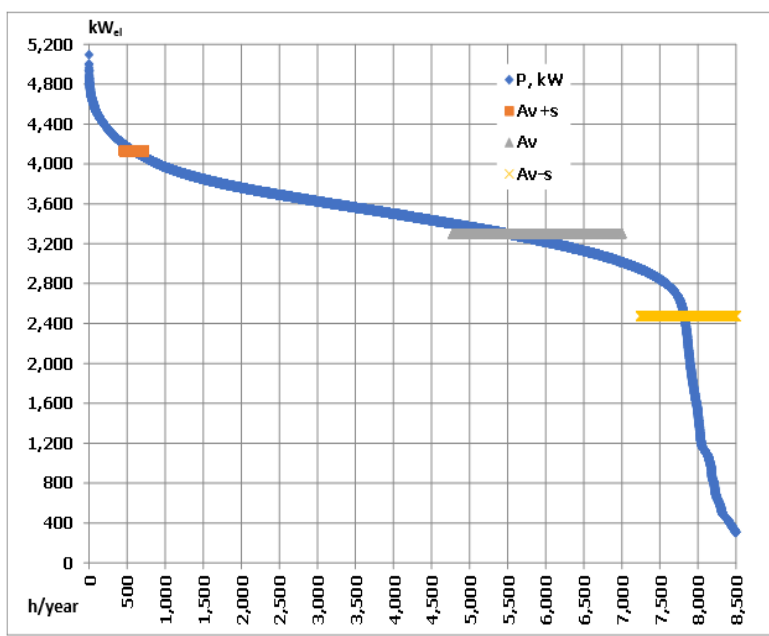

Fig. 1. Classified curve for the electricity demand.

From the allure of the ranked curve and the characteristic instantaneous values of the electrical power results a degree of flattening $(\delta)$ of 0.65 . It is also noted that the allure of the rated power curve is close to that of a Gaussian distribution. As a result, the "average mean deviation" of both the average and the average values was calculated, which was $\pm 827.9 \mathrm{kWe}$. It has been shown that the power range with a probability of $70.71 \%$ is between 2,474.6 kWe and 4,130.4 kWe (see Table 1).
Table 1. Characteristic values of electricity demand.

\begin{tabular}{|l|l|l|l|}
\hline Parameter & Notation & Value & Unit \\
\hline Maximum Power & $\mathrm{P}_{\text {el max }}$ & 5094,3 & $\mathrm{~kW}$ el \\
\hline $\begin{array}{l}\text { Average Power (on the } \\
\text { analysed range) }\end{array}$ & $\mathrm{P}_{\text {el med }}$ & 3302,5 & $\mathrm{~kW}$ el \\
\hline Minimum power & $\mathrm{P}_{\text {el min }}$ & 154,1 & $\mathrm{~kW}$ el \\
\hline $\begin{array}{l}\text { Average standard deviation } \\
\text { from the mean }\left(\mathrm{A}_{\mathrm{v} \pm \mathrm{s}}\right)\end{array}$ & $\Delta \mathrm{P}_{\text {el st dev }}$ & $\pm 827,9$ & $\mathrm{~kW}$ el \\
\hline $\begin{array}{l}\text { The power range with } \\
\text { probability of } 70.71 \%\end{array}$ & $\mathrm{P}_{\text {el med }} \Delta \mathrm{P}_{\text {el st dev }}$ & 2474,6 & $\mathrm{~kW}$ el \\
\cline { 2 - 4 } & $\mathrm{P}_{\text {el med }}+\Delta \mathrm{P}_{\text {el st dev }}$ & 4130,4 & $\mathrm{~kW}$ el \\
\hline
\end{tabular}

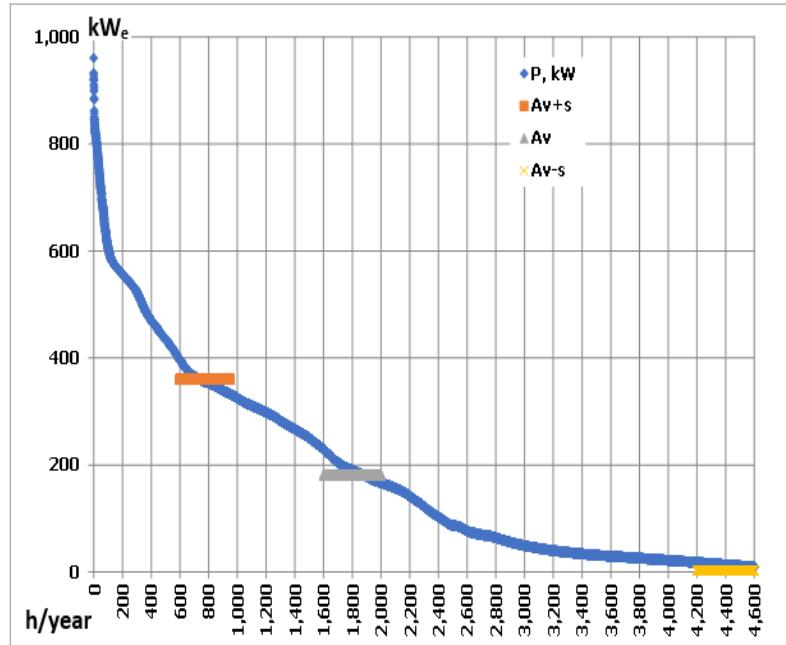

Fig. 2. The yearly cooling consumption curve load (electricity for chillers).

From the analysis of the ranked cooling curve, a cooling capacity of $4,692 \mathrm{~h} /$ year was achieved. In the allotted curve and the characteristic instantaneous values of the electric power for the chillers, a very low degree of flattening $(\delta)$ of 0.19 can be observed. The average power output was exceeded for a low duration of about $1900 \mathrm{~h} /$ year.

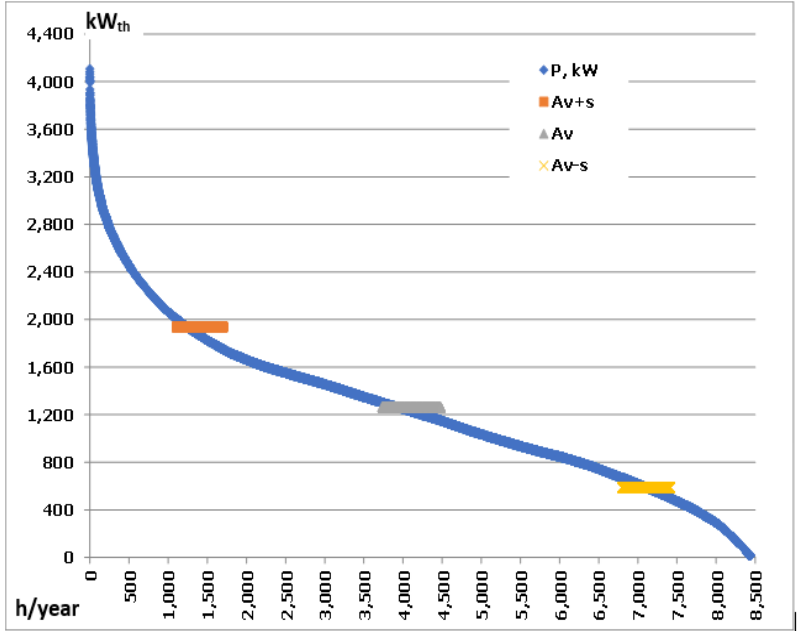

Fig. 3. Annual heat consumption curve. 
The processed statistical data cover a total equivalent time of 349 days, representing $95.56 \%$ of the total of 365 days / year. The characteristic instantaneous values (maximum, mean, minimum) are shown in Table 2.

From the allured curve and the characteristic instantaneous values of thermal power (heat), a low degree of flattening $(\delta)$ of 0.31 was obtained. The main disadvantage resulting from the analysis of the ranked curve is that we have a low average use of average thermal power. The average power value corresponds to a maximum power usage time of approximately $4,250 \mathrm{~h} /$ year.

Table 2. Characteristic values of the total heat demand.

\begin{tabular}{|l|l|l|l|}
\hline Parameter & Notation & Value & Unit \\
\hline Maximum Power & $\mathrm{P}_{\text {th } \max }$ & 4107,0 & $\mathrm{~kW}$ th \\
\hline $\begin{array}{l}\text { Average Power } \\
\text { analysed range) }\end{array}$ & $\mathrm{P}_{\text {th med }}$ & 1262,5 & $\mathrm{~kW}$ th \\
\hline Minimum power & $\mathrm{P}_{\text {th min }}$ & 15,1 & $\mathrm{~kW}$ th \\
\hline $\begin{array}{l}\text { Average standard deviation } \\
\text { from the mean }\left(\mathrm{A}_{\mathrm{v} \pm \mathrm{s}}\right)\end{array}$ & $\Delta \mathrm{P}_{\text {th st dev }}$ & $\pm 674,3$ & $\mathrm{~kW}$ th \\
\hline $\begin{array}{l}\text { The power range with } \\
\text { probability of } 70.71 \%\end{array}$ & $\mathrm{P}_{\text {th med- }} \Delta \mathrm{P}_{\text {th st dev }}$ & 588,1 & $\mathrm{~kW}$ th \\
\cline { 2 - 5 } & $\mathrm{P}_{\text {th med }}+\Delta \mathrm{P}_{\text {th st dev }}$ & 1936,8 & $\mathrm{~kW}$ th \\
\hline
\end{tabular}

Correlating the analysis of the energy curves (Figures 1-3), the following observations can be highlighted:

- Simultaneous demand for electricity and heat has an important effect on the performance of the core cogeneration plant within the trigeneration plant, thus a good degree of simultaneity favours the positive effect of cogeneration (the basic solution in the case under consideration) and increases the overall yield to be achieved.

- High electricity consumptions have been registered, mostly higher than the average $(3,300 \mathrm{kWel})$ in the hot season (end of spring - summer - beginning of autumn); these are due to the demand for mechanical energy of the "reversed cycle" thermodynamic plants used to produce the cold.

\section{Energy evaluation of technological solutions for trigeneration and selection of the optimal solution}

\subsection{Analysis of the possible basic technological solutions (cogeneration)}

The basic technological solutions for cogeneration are the gas turbine (GT) or the internal combustion engine (ICE); in both cases, cogeneration being recuperative does not influence the conversion of heat input in mechanical work, which influences in a positive sense the efficiency of electricity production.

Due to the high temperature of the flue gases discharged from the gas turbine (GT), the coefficient of recovery of the sensible heat of the combustion gases is higher than that of the piston engine (ICE) and the entire recovered heat can be used for the production of steam, requirement imposed by the heat consumption structure within the considered industrial framework.
For the above-mentioned reasons, an open-cycle gas turbine is proposed as a cogeneration technology solution. A first advantage of gas turbine (TG) open circuit is that the recovery of the exhaust heat from the cycle does not influence the performance of the working cycle. In other words, the electrical power that can be delivered to the generator's terminals does not depend on the amount and parameters of the heat recovered, as is the case of the steam turbines. Thus, at lower thermal inputs than recoverable heat, part of the exhaust gas can bypass the Heat Recovery Steam Generator (HRSG). In this way, the electricity production may continue, but as a consequence the overall efficiency of the fuel use decreases.

For the technical and energy considerations that recommend the gas turbine technology solution, the following advantages of this technological solution are added [5]:

- starting and charging times are very low compared to steam turbines at the same capacity;

- smaller size comparing with other solutions, so they can be placed in limited spaces;

- investments are relatively low (about $50 \%$ of those corresponding to steam turbines at the same capacity);

- the amount of water required for cooling is minimal;

- it has a high degree of pre-assembly and therefore the assembly time is very short;

- "clean technologies" for energy production, given the reduced specific emissions guaranteed by manufacturers compared to other cogeneration technologies of the same capacities.

The thermodynamic and technical performances that are considered in the choice of GT are:

- the rated power at the generator terminals, $\mathrm{P}_{\mathrm{bg}}\left[\mathrm{kW}_{\mathrm{el}}\right]$ (in the present case, a value below $4 \mathrm{MW}$ can provide a load close to the nominal value, without the sale of electricity to the grid);

- the efficiency of electricity production; $\eta_{\text {el bg }}[\%]$ (as high as possible to reduce fuel consumption);

- the temperature of the flue gases at the evacuation from GT, $\operatorname{tga}_{\mathrm{gav}}\left[{ }^{\circ} \mathrm{C}\right]$ (increasing it ensures the possibility of producing superheated steam with higher parameters without reducing the maximum recovery of the heat exhausted from the thermodynamic cycle.

Following the analysis of the preliminary results, a gas turbine produced by Centrax Gas Turbines, having the company code CX501-KB5 and the data presented in Table 3, was selected.

Table 3. Characteristic data (catalogue \& calculated) for the CX501-KB5 GT, produced by Centrax Gas Turbines.

\begin{tabular}{|c|c|c|c|c|c|c|c|}
\hline 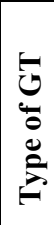 & 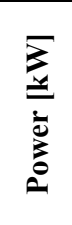 & 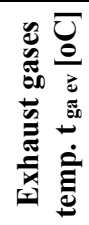 & 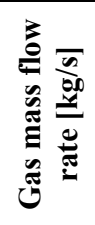 & 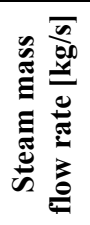 & 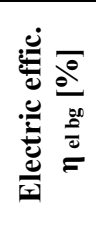 & 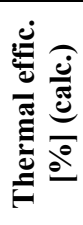 & 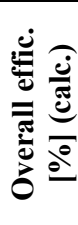 \\
\hline$\underset{\Xi}{\Xi}$ & $\begin{array}{c}3,95 \\
0\end{array}$ & 555 & 0.284 & 2.312 & 29.04 & $\begin{array}{c}56.4 \\
7\end{array}$ & $\begin{array}{c}85.5 \\
1\end{array}$ \\
\hline
\end{tabular}

The results of the calculations are presented in tabular 
form (Table 4 and Table 5) and graphics (Figures 4 and $5)$.

Table 4. The data for the $t$-q diagram of HRSG.

\begin{tabular}{|c|c|c|c|}
\hline $\begin{array}{c}\text { Exhaust gases } \\
\text { temperatures } \\
{\left[{ }^{\mathbf{}} \mathbf{C}\right]}\end{array}$ & $\begin{array}{c}\text { Water-steam } \\
\text { temperatures } \\
{\left[{ }^{\circ} \mathbf{C}\right]}\end{array}$ & $\begin{array}{c}\text { Percentage } \\
\text { of } \mathbf{Q}_{\text {transferred }} \\
{[\mathbf{\%}]}\end{array}$ & $\begin{array}{c}\text { Transferred } \\
\text { heat } \\
{[\mathbf{k W}]}\end{array}$ \\
\hline 97.60 & 40.00 & 0.00 & 0.00 \\
\hline 187.45 & 162.45 & 19.64 & 1,508 \\
\hline 187.45 & 172.45 & 19.64 & 1,508 \\
\hline 543.65 & 172.45 & 97.52 & 7,486 \\
\hline 555.00 & 185.41 & 100.00 & 7,676 \\
\hline
\end{tabular}

Table 5. Data for Energy Flow Diagrams (Sankey type) for the GT+HRSG.

\begin{tabular}{|c|c|c|c|c|c|c|}
\hline \multirow{2}{*}{ : } & \multicolumn{2}{|c|}{$\begin{array}{c}\text { GT inlet } \\
\text { energy } \\
\text { streams }\end{array}$} & \multicolumn{2}{|c|}{$\begin{array}{c}\text { GT outlet } \\
\text { energy } \\
\text { streams }\end{array}$} & \multicolumn{2}{|c|}{$\begin{array}{c}\text { HRSG outlet } \\
\text { energy } \\
\text { streams }\end{array}$} \\
\hline & $\%$ & MW & $\%$ & MW & $\%$ & MW \\
\hline $\mathrm{P}_{\mathrm{tc} \mathrm{CA}}$ & 100 & 13.6 & & & & \\
\hline$\Delta \mathrm{P}_{\mathrm{GA} \mathrm{rec}}$ & & & & & 10.87 & 1.43 \\
\hline $\mathrm{P}_{\mathrm{t} \text { rec GA }}$ & & & & & 56.46 & 7.68 \\
\hline$\Delta \mathrm{P}_{\text {csga TG }}$ & & & 67.33 & 9.11 & & \\
\hline $\mathrm{P}_{\mathrm{bg}}$ & & & 29.05 & 3.95 & & \\
\hline$\Delta \mathrm{P}_{\text {gen }}$ & & & 1.05 & 0.14 & & \\
\hline$\Delta \mathrm{P}_{\mathrm{mec}}$ & & & 0.96 & 0.13 & & \\
\hline$\Delta \mathrm{P}_{\mathrm{CA}}$ & & & 1.60 & 0.26 & & \\
\hline
\end{tabular}

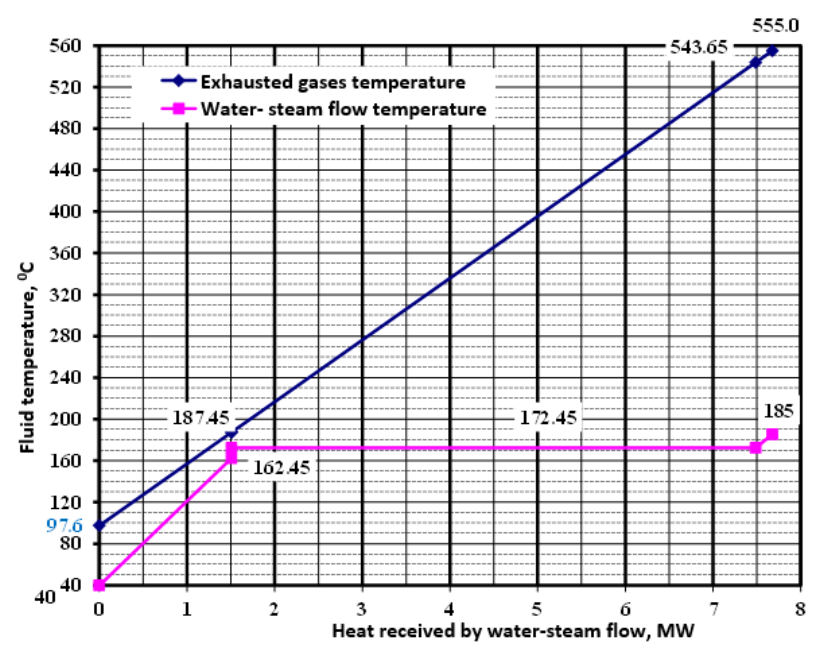

Fig. 4. Diagram t-q of HRSG, without post-combustion, in absolute sizes.

Table 6. Explaining the notations used in energy flow diagrams (Sankey type) for the GT + HRSG.

\begin{tabular}{|l|l|}
\hline $\mathbf{P}_{\text {tc CA }}$ & Heat generated by fuel combustion at GT \\
\hline$\Delta \mathbf{P}_{\mathbf{C A}}$ & GT Heat losses by radiation, convection \\
\hline$\Delta \mathbf{P}_{\text {mec }}$ & GT mechanic losses, including speed reducer \\
\hline$\Delta \mathbf{P}_{\text {gen }}$ & GT electric generator losses \\
\hline $\mathbf{P}_{\mathbf{b g}}$ & GT Power at generator clamps \\
\hline $\boldsymbol{\Delta} \mathbf{P}_{\text {csga TG }}$ & Heat released with exhaust gases \\
\hline $\mathbf{P}_{\text {t rec GA }}$ & $\begin{array}{l}\text { Heat recovered by the HRSG from exhaust } \\
\text { gases }\end{array}$ \\
\hline $\mathbf{\Delta}_{\text {GA rec }}$ & $\begin{array}{l}\text { Heat losses at HRSG trough radiation and } \\
\text { exhaust gases at the chimney }\end{array}$ \\
\hline
\end{tabular}

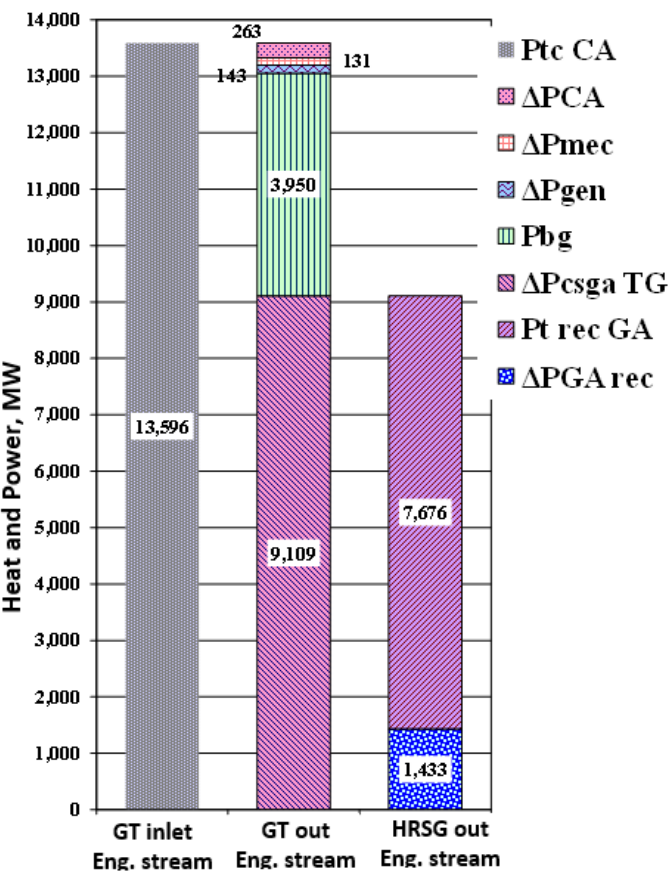

Fig. 5. Sankey diagram for $\mathrm{TG}+\mathrm{GA}$ recovery set, in absolute sizes [MW].

\subsection{Choice of the trigeneration plant solution for energy supply of the industrial consumer}

Considering the way of ensuring the need for cooling, technical solutions can be formulated from the basic technological solution of cogeneration - gas turbine.

Solution 1: GT - ARP

The heat produced in cogeneration mode within the gas turbine system is used for:

- ensuring the technological heat demand, in the form of saturated steam ( 8 bar), produced in the exhaust-heat boiler (located in the flue gas flow at the gas turbine outlet);

- provision of the necessary cooling for the air conditioning of the premises (production halls and administrative buildings, produced in an absorption refrigeration plant (ARP);

- providing the heat necessary to heat the spaces (production halls and administrative buildings) in the form of hot water - produced in a steam-water heat exchanger, the steam being produced by the exhaust-heat boiler;

- the electricity produced in cogeneration covers the electricity needed for the technological production facilities, the utilities of the company, and the overproduction (depending on the coverage of the ranked electricity demand curve) can be sold, bringing economic benefits.

Solution 2: GT - VCRS

The heat produced under cogeneration in the gas turbine installation (GT) is used in the same way as for the previously described solution.

The cold is produced in this variant in a vapor compression refrigeration system (VCRS) [6]. 


\section{Economic evaluation of proposed trigeneration solutions}

In the comparative economic analysis of the proposed technological solutions for trigeneration, the investments, expenses and annual receipts used for the calculation of the updated economic indicators (the updated net present value - NPV, the recovery period - RP and the internal rate of return - IRR) were determined [7,8]. The obtained results are presented in Table 7 and Figures 6 and 7 .

Table 7. Economic evaluation of the proposed technological solutions.

\begin{tabular}{|l|c|c|c|}
\hline Indicator & Units. & GT-ARP & GT -VCRS \\
\hline Investment & {$[€]$} & $2,716,446$ & $2,596,446$ \\
\hline Costs & {$[€]$} & $3,913,207$ & $3,913,207$ \\
\hline Incomes & {$[€ /$ year] } & $4,458,297$ & $4,458,297$ \\
\hline NPV & {$[€]$} & $1,924,213$ & $2,044,213$ \\
\hline IRR & {$[\%]$} & 19 & 20 \\
\hline RP & {$[$ years $]$} & 8 & 7.8 \\
\hline
\end{tabular}

Considerations and calculation assumptions:

- $\quad$ discount rate, $\mathrm{a}=10 \%$;

- $\quad$ study duration, $\mathrm{t}_{\mathrm{s}}=20$ years;

- investments are made in one year;

- annual electricity and heat outputs are considered to be constant (hence the incomes and expenses do not change).

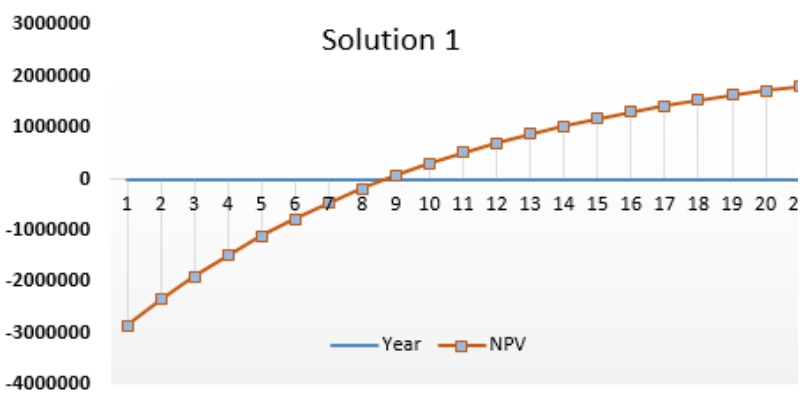

Fig. 6. NPV indicator for Solution 1 (GT - ARP).

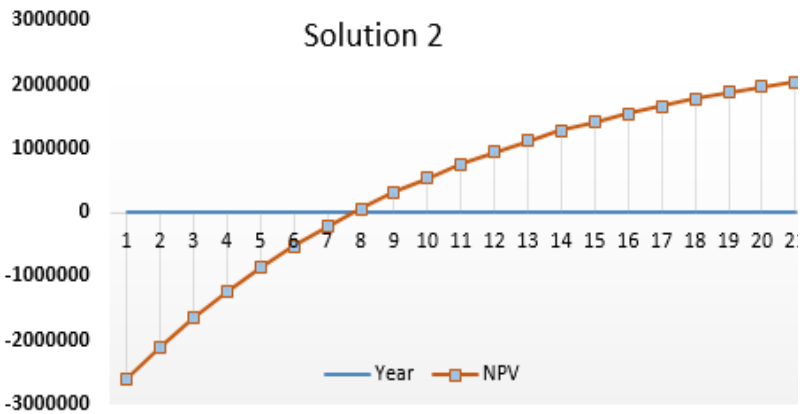

Fig. 7. NPV indicator for Solution 2 (GT - VCRS).

\section{Analysis of the results obtained and conclusions}

The original contribution of the authors is to develop a methodology of technical and economic analysis, with a unitary character from both a structural point of view and the degree of flexibility in the applications in which it is used. This methodology represents a module of the feasibility study that precedes the implementation of a trigeneration plant.

The validation of the methodology, respectively of the "technical-economic analysis module", was carried out on a concrete application (energy consumption values, specific conditions).

The paper aims the realization of a technical-economic analysis of the opportunity of implementing the trigeneration solution for the supply of an industrial consumer, compared to the separate supply with electric energy, heat and cold.

The technological alternatives of cold production analysed in this paper are the only technically possible solutions for the studied application, and their comparative analysis was done only from the economic point of view.

Increasing the energy efficiency by implementing the combined and simultaneous energy supply of the company in the trigeneration regime is also influenced by the shape of the classified curve of the thermal energy demands in the form of heat and cold.

Their configuration illustrates the fact that during the warm season, the use of exhausted heat to obtain cold is a viable solution because the demand for heat is very low during this time. During this period, according to the classified curve, the demand for cooling reaches its highest values.

It should be noted that, in an absorption refrigeration plant, a flow rate of about $1-1.2 \mathrm{t} / \mathrm{h}$ of steam is required to obtain $1 \mathrm{MW}$ thermal energy in the form of cold. Heat flows as steam available through the chosen technological solution ensure the production of the required cooling demand of the analysed industrial consumer.

Also, given the fact that the ARP needs a period of time to reach the nominal operating mode after starting, a cold-water tank should be provided in the scheme as a buffer for the transient periods or in case of accidental stop. This fact will be reflected in the economic evaluation, the values of the economic indicators recommend as optimal technical-economic solution the trigeneration plant in which the cooling is provided by a vapor compression refrigeration system (GT - VCRS).

In the methodology of evaluation of the optimal technical and economic solution were taken into consideration both economic factors specific to the proposed technological solution and the factors specific to the economic environment in which the new trigeneration plant will operate.

The most important economic factors specific to the proposed technological solution are:

- total investment in the trigeneration plant;

- the lifetime of the gas turbine (GT) within the trigeneration plant; 
- yearly use of installed electrical and thermal capacities;

- $\quad$ fixed costs (maintenance, salaries, materials);

Among the factors characteristic for the economic environment, which can influence the economic hierarchy of the proposed solutions are:

- the price of available fuel (natural gas);

- the price of the electricity purchased (or replaced);

- the price of electricity sold to the public grid and other restrictions which result from this relationship;

- taxes and duties applied to self-producers of electricity and possible ecotaxes.

The comparative economic evaluation of the two considered trigeneration technology solutions based on the calculated values (Table 7) of the updated economic indicators (NPV, IRR and RP) establishes the Solution 2 (GT-VCRS) as the optimal one.

The difference between the values of the indicators of the two analysed technological solutions is not significant, so the factors characteristic of the economic environment can influence the economic hierarchy of the proposed solutions.

By implementing a trigeneration solution that uses technology-efficient and energy-efficient equipment with low impact to the environment, the reduction of the global energy bill of the company and consequently the increasing of its profit can be reached.

\section{References}

1. V. Athanasovici, I.S. Dumitrescu, R. Pătraşcu, I. Bitir, E. Minciuc, F. Alexe, V. Cenuşă, C. Răducanu, C. Coman, C. Constantin, Energy supply handbook. Heat supply, Cogeneration, (AGIR, 2010)

2. M.M. Ghafurian, H. Niazmand, Int. J. of Refrig. 86, 89 (2018) https://www.sciencedirect.com

3. L.F. Fuentes-Cortes; J.M. Ponce-Ortega, Eng. Conv. and mang., 151, 43(2017) http://isiarticles.com

4. A. Rong, Y. Su, Eng. and build., 151, 439 (2017) https://www.sciencedirect.com

5. D. Sonar, S.L. Soni, D. Sharma, Appl. Th. Eng., 71, 790 (2014) https://www.sciencedirect.com

6. G. Ciampi, A. Rosato, M. Scorpio, Appl. Th. Eng., 73, 1309 (2014) https://www.sciencedirect.com

7. R. Pătraşcu, C. Răducanu, I.S. Dumitrescu, Energy use, (BREN, Bucharest, 2004)

8. M. Toropoc, R. Frunzulică, Efficiency, comfort, energy conservation and environment protection, (2008) 